\title{
Giant Cell Lesion and Central Giant Cell Granuloma of Jaw: A Brief Review
}

\author{
Nilesh Kumar ${ }^{1 *}$, Aaditee V. Vande ${ }^{2}$, Shivsagar Tewary² and Sameer Anil Zope ${ }^{3}$ \\ ${ }^{1}$ Department of Oral \& Maxillofacial Surgery, School of Dental Sciences, KIMSDU, Karad, Maharashtra, India. \\ ${ }^{2}$ Department of Prosthodontics, School of Dental Sciences, KIMSDU, Karad, Maharashtra, India. \\ ${ }^{3}$ Department of Periodontics, School of Dental Sciences, KIMSDU, Karad, Maharashtra, India.
}

\section{ABSTRACT}

This review discusses giant cell lesion with main focus on central giant cell granuloma of jaw. Review of the lesion with regard to its nomenclature, pathogenesis and its clinical, radiological \& histopathological features is presented. Surgical therapy along with recently reported conservative management protocol is discussed in detail.

Keywords: Craniofacial, Oral Pathology, Intraosseous Lesion

\section{Introduction}

Giant cell lesion comprises an interesting and controversial group of lesion, characterized by presence of giant cells in their histological section. Giant cells are cells with more than one nucleus. These cells are found in many physiological as well as pathological conditions. It is multinucleated and larger in size in comparison to other body cell. Two main mechanisms have been proposed for the formation of multinucleated giant cell; multinuclear division without cytokines and fusion of multiple cells. The precursor of giant cell remains unknown. However it is believed to be derived from osteoclast and macrophage. They are found in variety of lesions, which range from reactive pathology to neoplasm and from cyst to hormone related disorders. All these lesions are characterized by presence of giant cells histologically (table 1). Though giant cells are found in variety of diseases and conditions, it is not a characteristic or pathognomonic feature of all such lesions. Lesions in which Giant cells are a characteristic histological feature are grouped under giant cell lesion.

\section{Classification of Giant Cell Lesions of Oral Cavity}

Significant controversy exists regarding classification of giant cell lesion of maxillofacial region (table 2). Based on its location it can be intraosseous (e.g. central giant cell granuloma) or extraosseous (e.g. peripheral giant cell granuloma). The amount on giant cells is variable in various groups of diseases. Based on propensity in which giant cells are present it can be classified as; true giant cell lesion (lesion with predominant giant cells) which include central giant cell granuloma, peripheral giant cell granuloma, giant cell tumor and giant cell lesion of hyperparathyroidism. Giant cell lesion with moderate number of giant cells includes cherubism, giant cell granuloma of Paget's disease and aneurysmal bone cyst. Fibrous dysplasia and pyogenic granuloma have minimal number of giant cells. Clinically it may be benign or malignat. Benign lesion are either non-aggressive (e.g. central giant cell granuloma) or aggressive (aggressive variant of Central giant cell granuloma). Malignant giant cell lesion include metastatic giant cell tumor.

Table 1: Variety of lesions having Giant cells:

\begin{tabular}{|l|}
\hline 1. Infections \\
Bacterial (T.B., Leprosy, Syphilis) \\
Viral (Measles, HSV infections, Herpetic \\
Gingivostomatitis) \\
Fungal (Candidiasis, Blastomycosis, Histoplasmosis) \\
Parasitic (Leismaniasis) \\
\hline 2. Fibro-osseous lesions \\
Cherubism \\
Paget's disease \\
Fibrous dysplasia \\
\hline 3. Reactive lesion \\
Central giant cell granuloma \\
Peripheral giant cell granuloma \\
Periapical granuloma \\
\hline 4. Hormonal lesion \\
Brown tumor of Hyperparathyroidism \\
\hline 5. Cystic lesion \\
Traumatic bone cyst \\
\hline 6. Neoplastic lesions \\
Benign neoplasm (Giant Cell Tumor) \\
Malignant neoplasm (Osteosarcoma, Chondrosarcoma) \\
\hline
\end{tabular}


Table 2: A working classification of giant cell lesion of the oral cavity

\begin{tabular}{l} 
1. Lesions where giants cells are pathognomonic \\
i. Central giant cell granuloma \\
ii. Peripheral giant cell granuloma \\
iii. Giant cell tumor \\
iv. Giant cell lesion of Hyperparathyroidism \\
\hline 2. Lesions where giant cells are characteristic \\
i. Cherubuism \\
ii. Giant cell granuloma of pagets disease \\
iii. Aneurysmal Bone Cyst \\
\hline 3. Lesion associated with presence of giant cells \\
i. Orofacial granulomatosis \\
ii. Foreign body reaction \\
iii.Fibrous Dysplasia \\
\hline
\end{tabular}

\section{Central Giant Cell Granuloma (CGCG)}

W.H.O. defines CGCG as an intraosseous lesion consisting of fibrous tissue that contains multiple foci of hemorrhage, aggregation of multinucleated giant cells and occasionally trabeculae of woven bone.

Nomenclature: CGCG of jaws in past were grouped under giant cell tumor. Re-evaluation of the lesion suggested that is reparative and is formed in response to injury. Jaffe named this group of lesion as central giant cell reparative granuloma [1]. He believed the lesion was a reparative response to injury rather than neoplasm. General dissatisfaction with the term central giant cell reparative granuloma has been expressed by many authors. Waldron and Shafer pointed out that; the lesions are not a reparative process and comment that 'it does not seem logical that a destructive, locally invasive and potentially continuously enlarging lesion could represent a reparative' reaction. Most oral \& maxillofacial pathologists have dropped the term 'reparative'. Today these lesions are designated as 'central giant cell granuloma' or by a more non-committal term 'giant cell lesion'

Etiopathogenesis: The cause of CGCG continues to be a mystery. These lesions do not fit into the concept of either reactive or neoplastic disease, and as a group may exhibit feature of both. Jaffe was the first to separate CGCG from the giant cell tumor. He believed CGCG to be a reactive / reparative lesion arising subsequent to injury. However current experience indicates that giant cell lesion of jaws exhibits a range of activity from that of a reparative granuloma to that of an aggressive neoplasm. How to distinguish between them remains unanswered. Perhaps there is a reactive and a neoplastic form of CGCG (as group exhibit features of both). Alternatively one could speculate that the subset of tumors that behave as a neoplasm develop from a reactive (reparative) lesion though an epigenetic event occurring in the spindle mesenchyme cells of bone.

CGCG are composed of a large number of monocyte derived multinucleated giant cell osteoclasts in a stroma of mononuclear spindle shaped mesenchymal cells. While giant cell is a prominent feature of these lesions, it is the mononuclear spindle cells that are the proliferating cells (neoplastic cells) in CGCG. It is believed that spindle cells recruits monocytes and induces them to differentiate into osteoclastic giant cells through the release of cytokines (figure 1). Osteoblast mediated bone resorption and proliferation of spindle cells leads to the growth of CGCG.

Clinical Features: CGCG is a rare tumor of jaw and accounts to about $7 \%$ of benign jaw tumors. It is exclusively seen in the jaws (not found in extragnathic skeleton). It predominantly occurs in children and young adults (common in $1^{\text {st }}$ to $3^{\text {rd }}$ decade of life). It is more common in females than in males (in ratio of 3-2: 1). Either jaw may be involved, but mandible is more commonly involved than maxilla (60-70\% of the reported cases arises in mandible). It is commonly seen in anterior portion of jaw [2].

Most giant cell granulomas of the jaw are asymptomatic and first come to notice during routine radiographic examination or as a result of painless expansion of bone. A minority of cases however may be associated with pain, parasthesia or perforation of the cortical bone plates, occasionally resulting in ulceration of mucosal surface by the underling lesion (figure 2). Displacement of tooth and increased tooth mobility may also be seen [3]. Based on the clinical and radiographical features, several groups of investigators have suggested that CGCG may be divided into two categories; non-aggressive lesion and aggressive lesion.

Non-aggressive lesion makes up most cases. It exhibits no or few symptoms (found on routine radiography). It demonstrates slow growth and usually does not show cortical perforation or root resorption of the teeth involved in the lesion. Aggressive lesion is characterized by pain, rapid growth, cortical perforation, root resorption, parasthesia (nerve involvement and perineural spread is rare though). It has marked tendency to recur after removal (as compared to non-aggressive type).

Radiographical Features: Radiographically CGCG appear as a radiolucent lesion, which may be unilocular or multilocular [4]. The radiolucency is usually well delineated, but the margins are generally non-corticated. The lesion may vary from small sized incidental finding on radiograph to large destructive lesion (Figure 3). The radiographic findings are not specifically diagnostic. 


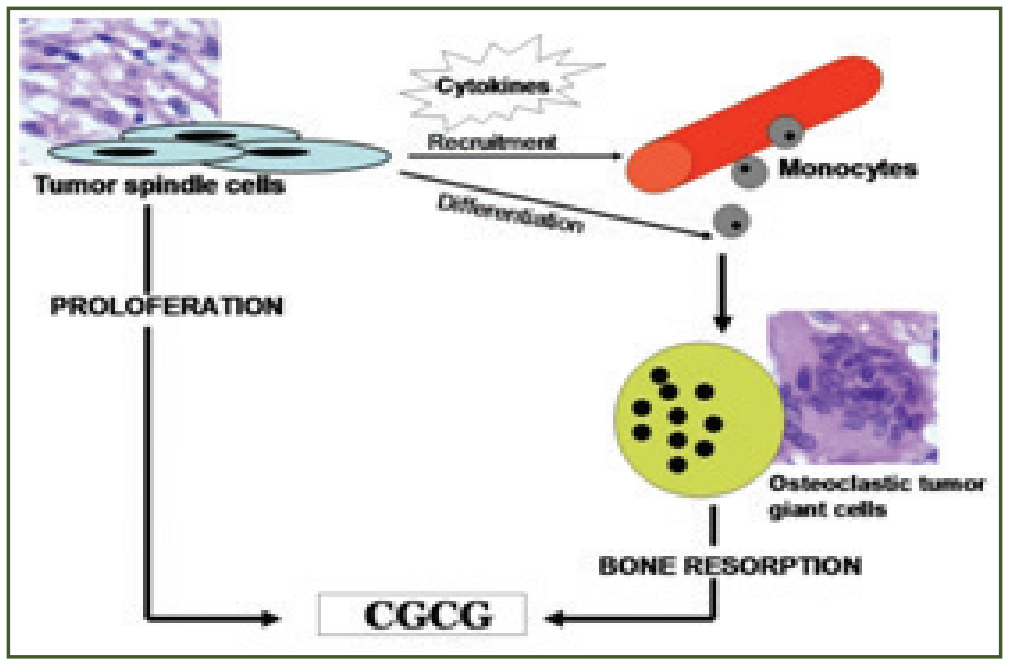

Fig. 1: Flow-chart explaining the pathogenesis of CGCG

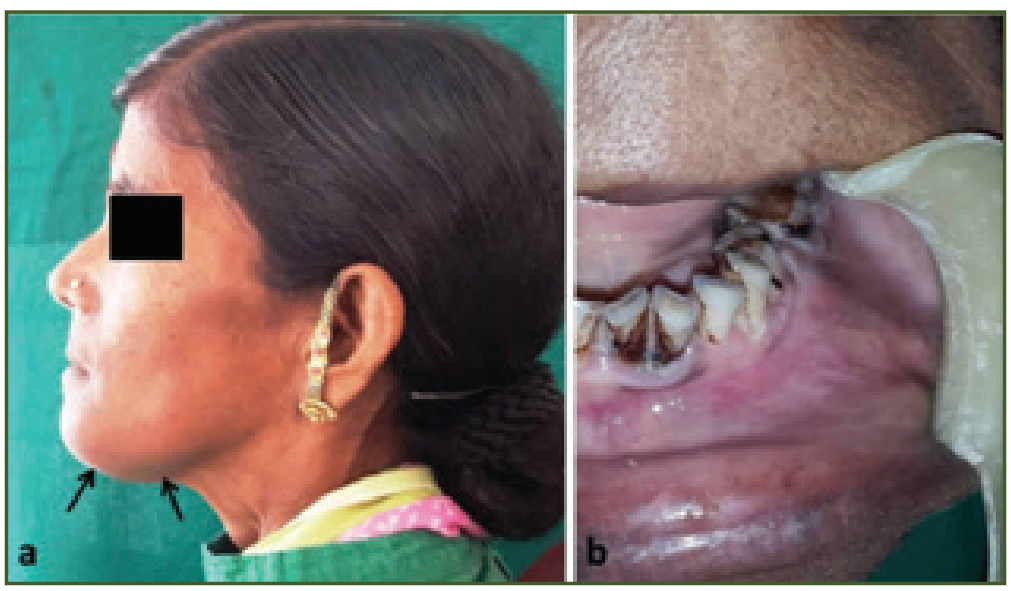

Fig. 2: Clinical presentation of the lesion as extra-oral swelling (a), intra-oral view showing buccal cortical bone expansion.

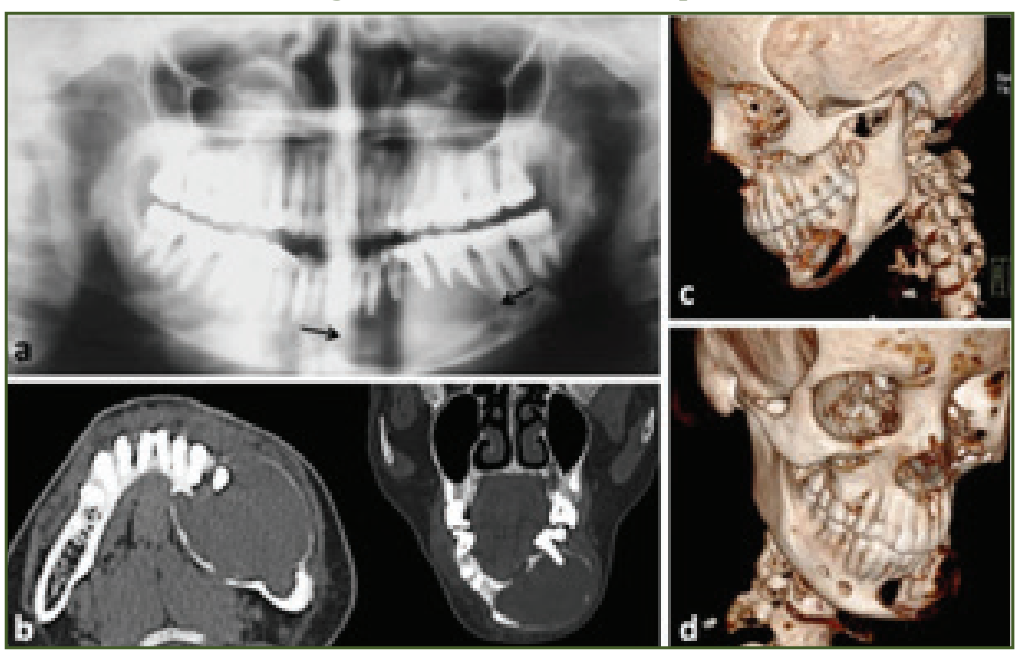

Fig. 3: Radiological features of patient with CGCG in figure 2 showing a defined radiolucent lesion of mandible with resorption of involved tooth roots (a), sectional computed tomography images showing expansion and thinning of the cortical bones (b) and three dimensional formatted image of the lesion showing ballooning and resorption of mandible (c,d). 
Small unilocular lesions may be confused with periapical granuloma or cysts. Multilocular giant cell lesions can't be distinguished radiographically from ameloblastoma or other multilocular lesions. The multilocular or soap bubble radiolucent lesion appears similar to ameloblastoma, odontogenic myxoma, ameloblastic fibroma, etc. The septa between the loculations are usually fibrous in nature but occasionally may be residual, atrophied and remodeled trabeculae. A thin sclerotic rim is often seen at the periphery, which is typically scalloped. Expansion and thinning of the facial and to a lesser extent the lingual, cortex is common for the larger lesions and may be marked because the central giant cell lesion may achieve a large size over period of time (hyperparathyroidism should be suspected with large lesions). Enlargement is characteristically slow but may be alarmingly rapid in the early stages, especially if associated with infection, trauma (extraction) or hyperparathyroidism.

Differential Diagnosis: CGCG presents as swelling which appear as unilocular or multilocular radiolucency of jaw. The various differential diagnoses to be considered include $[5,6]$ :

- If the suspected region is in maxillary molar segment of the jaw, a multilobed maxillary sinus must be considered as the differential diagnosis, especially if the pattern is bilateral and the region is asymptomatic.

- If the lesion is situated in the posterior part of the mandible, in a patient over 30 years of age, it is more likely to be an ameloblastoma, especially if there is an accompanying paresthesia of lips.

- If the multilocular lesion is situated anteriorily in the jaws of the patient under 30 years of age, it is much more likely to be a giant cell granuloma than ameloblastoma

- If the patient complains of polydypsia and polyurea or has a history of renal disease along with abnormal serum calcium or phosphorous and alkaline phosphatase levels, the lesion is more likely to be $a$ giant cell lesion of hyperparathyroidism.

- If the lesion occurs in a child and is multiple, and if there is a family history of such lesion the diagnosis is most certainly cherubism.

Histological Feature: The central giant cell lesion is composed of mesenchymal stroma with moderate cellularity. The lesional cells appear as spindle-shaped or ovoid with moderate amounts of cytoplasm and a moderately large open nucleus. Collagen fibers are seen in variable amounts in the stroma along with multinucleated giant cells having randomly located nuclei (up-to 60 per cell, usually less than 10 per cell) scattered throughout. Focal areas of erythrocyte extravasation scattered throughout is usually seen. It is not unusual to see more blood outside vessels than within vessels. The lesion is described as a blood-soaked sponge with oozing blood. The focal hemorrhage gives the cut surface on gross examination a mottled tan and brown appearance. Hemosiderin deposits may be seen as a sign of old hemorrhage. The stroma has dense collagen in older lesions. Lesions in very young persons (less than 7 years of age) appear biologically active, with numerous mitotic figures. The stroma may also be myxomatous in some lesions or regions of lesions, and at least $10 \%$ of cases show reactive new bone formation, located especially toward the periphery of the lesion. Occasional areas of necrosis and healing mimic aneurysmal bone cyst, and some authors have considered these two lesions as simple variations of the same phenomenon [7].

The histological differential diagnosis for central giant cell lesion includes the brown tumor of hyperparathyroidism, aneurysmal bone cyst and cherubism. The lesion is, for all practical purposes, indistinguishable from the brown tumor, but it can be separated from the aneurysmal bone cyst because it lacks the large blood-filled spaces without endothelial lining of the latter lesion. Also, it does not have the connective tissue septae with embedded multinucleated giant cells which are so characteristic of the latter entity. The stroma of cherubism is much loose and less cellular than that of the giant cell lesion. Number of giant cells is considerably less, with often only a few surrounding occasional blood vessels. Extravasation of erythrocytes is not a feature of cherubism. Additionally, the clinical and radiographic presentation of cherubism is usually quite different, with multiple quadrants of involvement. The pathologist must, as usual, evaluate the stroma for signs of dysplasia which might indicate osteosarcoma or fibrosarcoma of bone.

Treatment and Prognosis: The traditional treatment of CGCG is surgical removal. However the extent of tissue removed ranges from simple curettage to enbloc resection. Curettage has been supplemented with peripheral ostectomy in many of the reported cases [8]. Treatment of CGCG with cryosurgery and radiation therapy has also been reported in literature. CGCG have also been treated by nonsurgical methods such as systemic dose of calcitonin and intralesional injection of corticosteroids.

Surgical Treatment: The surgical treatment of CGCG varies from simple curettage to enbloc resection depending on extent of tissue involvement. Small lesions may be curetted out completely, while large lesions should be biopsied first for histological confirmation of the diagnosis. 
Several sites should be selected for representative sampling of the lesion. As with all central lesions of the jaw, the pathologist should be furnished with clinical and radiographical details. If biopsy report confirms CGCG it can be treated by surgical excision. Local curettage is the conventional treatment of CGCG. However enbloc resection is treatment of choice for locally aggressive CGC (figure 4). The primary treatment of CGCG with no evidence of cortical perforation and when the mucosa appears to be clinically intact is through curettage via an intraoral approach under GA. The surgical steps in management of CGCG are enumerated below:

- The incisions are made at least $1 \mathrm{~cm}$ away from the radiographic extent of the lesion on either side.

- A classical buccal mucoperiosteal flap is commonly raised. The thin buccal bone overlying the lesion is removed (a reciprocating saw or micromotor driven bur is used to cut the cortical bone around the lesion).

- A through curettage is done to remove the entire lesion until clinically healthy appearing bone is encountered. Compartmental or separated lesions are rendered unilocular by excision of intervening bony septa (radiographs act as a guide to ensure that compartments of the lesion well insulated by bone are not overlooked). The lesion usually bleeds excessively. However on its complete removal the bleeding gets easily controlled.

- The bone cavity may be saucerised by reducing the height of its osseous walls, to facilitate visual and mechanical access.

- Peripheral ostectomy is performed by trimming the cancellous bone from the walls of bony defect $(0.5$ bone removed) using surgical burs.

- In some lesions hemorrhage may be troublesome but can be controlled by small, hot, wet dressings or iodine impregnated gauze pack. Bleeding usually stops after removal of the lesion.

- The teeth in the area of lesion should be preserved (such teeth should be endodontically treated before surgery). However if adequate bone support to the roots are lacking or recess are created by roots from which lesion can't be removed, the teeth should be extracted.

- After through debridment of the bone cavity and attaining hemostasis, the flap is repositioned and sutured. In case of large bony cavity, packing with ribbon gauze soaked in either whitehead varnish or iodoform paste is done (that is retained insitu with loose sutures for 4 to 5 days after surgery, to protect the wound from food and other debris and allow healing by secondary intention).
- If possible, pressure dressing should be applied to prevent hematoma formation.

- The patient is instructed to use frequent hot saline rinse starting the day after surgery to keep the wound free of food debris. All treated patients should be reviewed clinically and radiographically until healing is completed [9].

Medical Therapy: Besides the traditional surgical treatment of CGCG, an alternative medical line of treatment has been widely studied and used recently. The agents used for the treatment of CGCG are; calcitonin, corticosteroid and antiangiogenic drug (interferon). Non-surgical medical modality of treatment of CGCG is usually recommended for:

- Aggressive, large rapidly growing lesions; surgical removal of which will lead to mutilation of face and severe compromise in function, loss of tooth \& tooth germs (especially in children and young adults).

- In recurrent lesions, especially where the lesion recurs after multiple surgical excision.

- When lesion is large and/or is in close proximity to important vital structuresn (medical therapy can be used independently or as an adjunct to surgery to preserve the vital structure and prevent its damage).

Calcitonin Therapy: Giant cells in CGCG are osteoclasts. Indirect evidence of this was provided by the behavior of the giant cells in the cortical bone, showing bone excavation typical of osteoclasts. It has been shown that giant cells express calcitonin receptors. Calcitonin binds on these receptors and inhibits the osteoclastic activity of giant cells (figure 5). Calcitonin therapy for management of CGCG is base on these above findings. CGCG develop from mononuclear precursor cells, and as such are part of granulocyte/macrophage lineage or are of primarily fibroblastic origin. In this case the effect of calcitonin might be explained by the fact that calcitonin receptors are found on mononuclear cells as well. Calcitonin induces involution and inhibition of DNA synthesis in these cells.

Two forms of calcitonin are available for therapeutic use; salmon calcitonin and human calcitonin. Human calcitonin is preferred over salmon calcitonin as it has lower antigenic properties than animal calcitonin. Routes of administration include subcutaneous injection and nasal spray. After subcutaneous injection peak in plasma is reached in an hour, with half life of 70-90 minutes. Dosage for subcutaneous route is 100 IU per day, whereas nasal Spray measuring $200 \mathrm{IU}$ is administered per day for 12-24 months [10]. Therapy is continued until there is no further resolution of the lesion radiographically (resolution usually takes 12-24 months). 

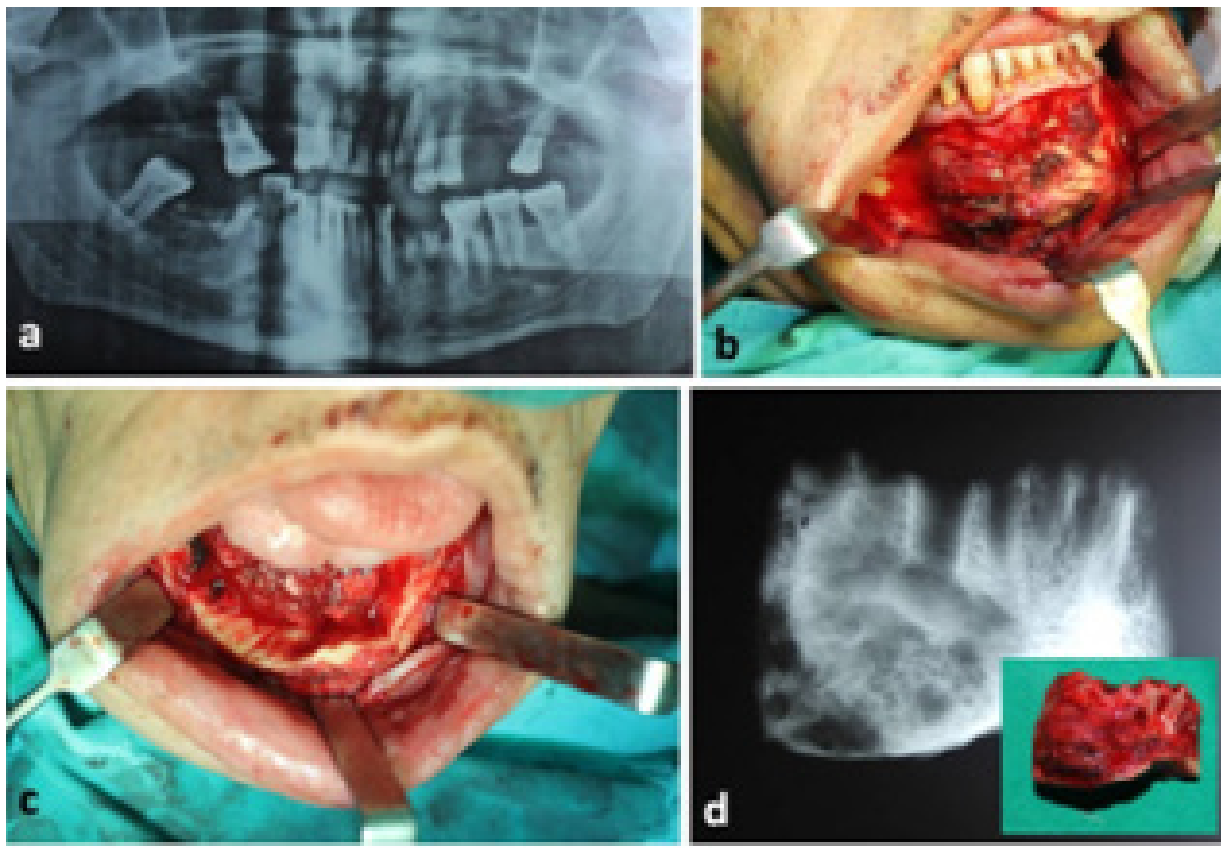

Fig. 4: Lesion involving the right parasymphis region of mandible (a), intraoperative view showing exposure of the pathology (b), enbloc resection of the lesion (c,d).

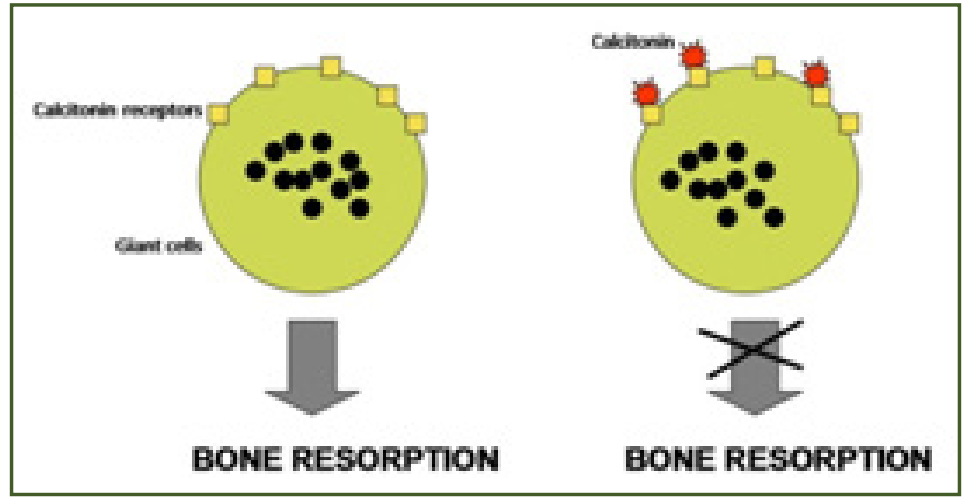

Fig. 5: Proposed mechanism of action of calcitonin.

Drawbacks of calcitonin therapy include the long duration of treatment. Recurrence after therapy is stopped have been reported if few cases. Side effects although usually minor and infrequent include; flushes, headache, diarrhea and nausea. Calcitonin as a therapy for CGCG of the jaws is a promising alternative to surgical curettage, particularly for large lesions [11]. Further investigations into dosage and duration of treatment are necessary before an optimal treatment protocol can be suggested.

Corticosteroid Therapy: Giant cell osteoclasts in CGCG accomplish bone resorption by secreting lysosomal proteases (e.g. cathepsin, gluccoronidsae). These proteases mediate osteoclastic bone resorption by creating an acidic extracellular medium. Steroids produce a dose dependent decrease in secreted levels of these enzymes (figure 6). In addition it has been experimentally shown that steroids induce apoptosis of osteoclasts. On basis of the above evidence, it is possible to hypothesize that the result obtained by using intralesional steroids in treatment of CGCG of the jaw bones may be due to; inhibition of extracellular production of lysosomal protease and steroidal apoptotic action on osteoclasts like cells [12]. Both the mechanism causes cessation of bone resorption in CGCG.

Treatment protocol of corticosteroid therapy includes:

Pretreatment biopsy is done to establish the diagnosis. Laboratory investigations of parathyroid hormone (PTH), calcium, and phosphorus are done to rule out hyperparathyroidism. An Intralesional injection is prepared 
of $50 \%$ mixture by volume of traimcinolone acetate $10 \mathrm{mg} /$ $\mathrm{mL}$ with $2 \%$ lidocaine. The solution is administered with a disposable syringe with $22 \mathrm{G}$ needle.

The average dosage of the solution is $6 \mathrm{~mL}$ for adults (equivalent to $30 \mathrm{mg}$ of triamcinolone) and $5 \mathrm{~mL}$ for the pediatric patients (equivalent to $25 \mathrm{mg}$ of triamcinolone) [13].

The solution is injected by clinically estimating the site where the cortical bone is more expanded and therefore, it is thinnest at that point. The bone is not trephinated. Once inside the lesion, the needle is redirected to inject small amounts into different areas.

The treatment is terminated when there is a significant amount of resistance caused by the bone being formed and calcified, thus avoiding the need for trephination.

Steroid therapy should not be used in patients with diabetes mellitus, peptic ulcer, infections and in immunecompromised patients [14].

Atiangiogenic Therapy (Using Interferon): Interferon (INF) is a cytokine with antiviral and anti-angiogenic properties. INF is either produced by recombinant DNA technology or it is purified from cultured human cells. Interferon alpha was the first angiogenesis inhibitor used. It is used in treatment of life threatening haemangiomas and other vascular tumors of various organs. The use of INF-alpha in CGCG is based on the hypothesis that CGCG's has proliferative vascular component. Though CGCG's are not true vascular lesion, it has a vascular component to it. In various published cases reports INF has been successfully used in combination with surgery for treatment of aggressive CGCG [15]. INF-alpha used as a monotherapy for aggressive CGCG was capable of terminating the rapid growth of the lesion. But only partial remission of the lesion is achieved in all reported cases, which stopped after few months $[16,17]$. The reason that total remission can't be achieved is probably due to the fact that the proliferating tumor cells are of fibroblastic origin (mononuclear spindle cells) and not endothelial cells. INF has no direct inhibiting effect upon the proliferating tumor cells. INF therefore seems capable of terminating the rapid growth and even causes regression, probably by inhibiting neo-angiogenesis in the lesion [18]. Dosage of interferon therapy in CGCG is 3,000,000 units $/ \mathrm{m}^{2}$ administered once per day by subcutaneous injection. Possible side effects of therapy include fever, flu like symptoms, lethargy, postnasal drip, skin rashes and hair loss [19].

\section{Conclusion}

Central giant cell granulomas are rare and a variable group of disorder. Its presentation varies from benign intraosseous pathology discovered on routine radiographs to more aggressive lesion presenting with large swelling, involvement of large area of jaw, tooth displacement along with involvement of surrounding vital structures. Knowledge of its pathogenesis and presenting features helps to effectively diagnose the condition. Conventional surgical intervention as well as more recently reported medical therapies has been successfully used for management of this pathology.

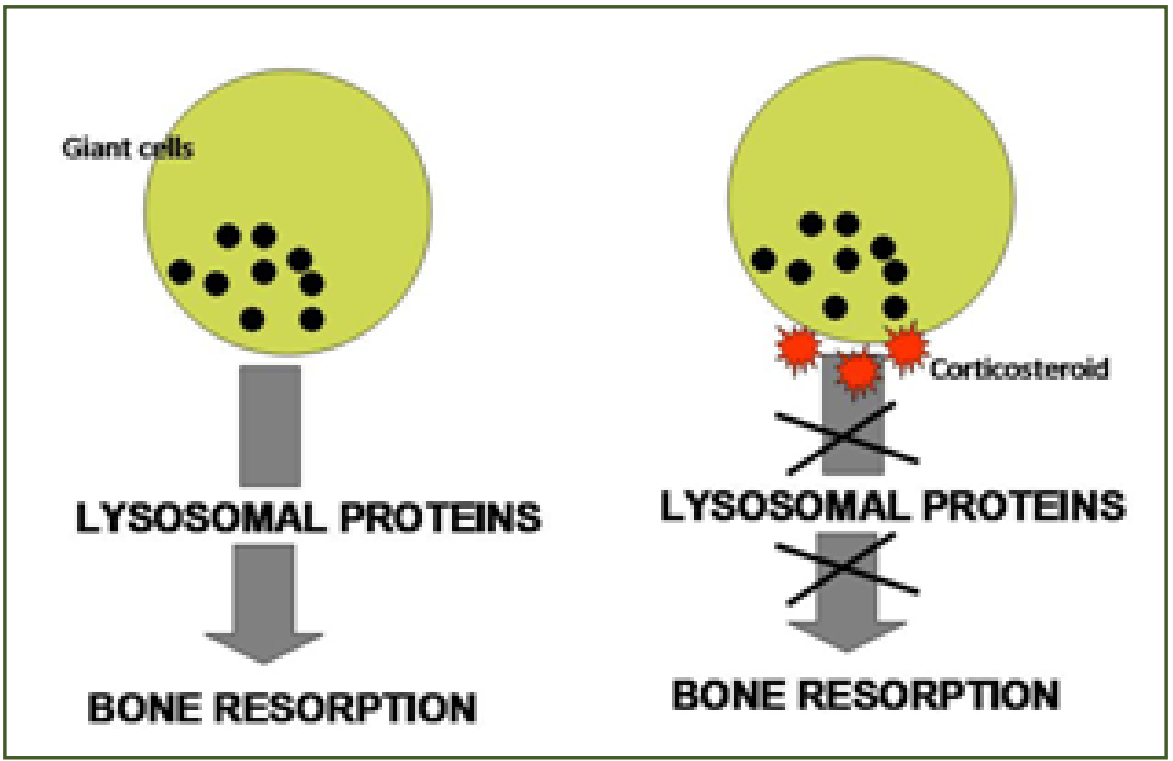

Fig. 6: Proposed mechanism of action of corticosteroid. 


\section{References}

1. Edwards PC, Fox J, Fantasia JE, Goldberg J, Kelsch RD. Bilateral central giant cell granulomas of the mandible in an 8-year-old girl with Noonan syndrome. Oral Surg Oral Med Oral Pathol Oral Radiol Endod 2005;99:334-40

2. De Lange J, Van den Akker HP. Clinical and radiological features of central giant-cell lesions of the jaw. Oral Surg Oral Med Oral Pathol Oral Radiol Endod 2005;99:464-70

3. Kruse-Lösler B, Diallo R, Gaertner C, Mischke KL, Joos U, Kleinheinz J. Central giant cell granuloma of the jaws: A clinical, radiologic, and histopathologic study of 26 cases. Oral Surg Oral Med Oral Pathol Oral Radiol Endod 2006;101:346-54

4. Ciorba A, Altissimi G, Giansanti M. Giant cell granuloma of the maxilla: case report. Acta otorhinolaryngol Ital 24, 2629, 2004

5. De Lange J, Van den Akker HP. Radiologic features of central giant cell granuloma of the jaw. Oral Surg Oral Med Oral Pathol Oral Radiol Endod 1996;81:720-6

6. Sidhu MS, Parkash H, Sidhu SS. Central giant cell granuloma of jaws-review of 19 cases. Br J Oral Maxillofac Surg. 1995 Feb;33(1):43-6.

7. Stavropoulos F, Katz J.Central giant cell granulomas: A systematic review of the radiographic characteristics with the addition of 20 new cases. Dentomaxillofac Radiol. 2002 Jul;31(4):213-7.

8. Bataineh AB, Al-Khateeb T, Rawashdeh MA. The Surgical Treatment of Central Giant Cell Granuloma of the Mandible. J Oral Maxillofac Surg. 2002 Jul;60(7):756-61.

9. Rawashdeh MA, Bataineh AB, Al-Khateeb T. Long-term clinical and radiological outcomes of Surgical management of central giant cell granuloma of the maxilla. Int $\mathrm{J}$ Oral Maxillofac Surg. 2006 Jan;35(1):60-6.

10. Pogrel MA. Calcitonin Therapy for Central Giant Cell Granuloma. J Oral Maxillofac Surg 61:649-653, 2003.
11. de Lange J, Rosenberg AJ, van den Akker HP, Koole R, Wirds JJ, van den Berg H. Treatment of central giant cell granuloma of the jaw with calcitonin. Int. J Oral Maxillofac. Surg. 1999; 28:372-376.

12. Kurtz M, Mesa M, Alberto P. Treatment of a central giant cell lesion of the mandible with intralesional glucocorticosteroids. Oral Surg Oral Med Oral Pathol Oral Radiol Endod 2001; 91:636-7.

13. Carlos R, Sedano HO. Intralesional corticosteroids as an alternative treatment for central giant cell granuloma. Oral Surg Oral Med Oral Pathol Oral Radiol Endod 2002; 93:161-6.

14. Adornato M., Paticoff K.A. Intralesional corticosteroid injection for treatment of central giant-cell granuloma. J Am Dent Assoc. 2001 Feb; 132(2):186-90.

15. de Lange J, van den Akker HP, van den Berg H, Richel DJ, Gortzak RA. Limited regression of central giant cell granuloma by interferon alpha after failed calcitonin therapy: a report of 2 case. Int J Oral Maxillofac Surg. 2006 Sep;35(9):865-9.

16. Kaban LB, Troulis MJ, Ebb D, August M, Hornicek FJ, Dodson TB. Antiangiogenic Therapy with Interferon Alpha for Giant Cell Lesions of the Jaws. J Oral Maxillofac Surg. 2002 Oct;60(10):1103-11;

17. Kaban LB, Mulliken JB, Ezekowitz RA, Ebb D, Smith PS, Folkman J. Antiangiogenic Therapy of a Recurrent Giant Cell Tumor of the Mandible with Interferon Alfa-2a. Pediatrics. 1999 Jun;103(6 Pt 1):1145-9

18. Kaban LB, Troulis MJ, Ebb D, August M, Hornicek FJ, Dodson TB. Antiangiogenic therapy with interferon alpha for giant cell lesions of the jaws. J Oral Maxillofac Surg. 2002 Oct;60(10):1103-11

19. Goldman KE1, Marshall MK, Alessandrini E, Bernstein ML. Complications of alpha-interferon therapy for aggressive central giant cell lesion of the maxilla. Oral Surg Oral Med Oral Pathol Oral Radiol Endod. 2005 Sep;100(3):285-91.

*Corresponding author:

Dr. Kumar Nilesh, Dept. of Oral \& Maxillofacial Surgery, School of Dental Sciences, Krishna Hospital, Karad, Satara , Maharashtra 415 110 INDIA Phone: +91 9158542384

Email: drkumarnilesh@yahoo.com

Date of Submission : 05.02.2017 